\title{
VIABILIDADE ECONÔMICA DO PLANTIO DE EUCALIPTO VM01 PARA PRODUÇÃO DE LENHA
}

Stephany Diolino Cunha ${ }^{1}$, Pedro Henrique França Grupioni ${ }^{1}$, Andrécia Cósmen da Silva $^{2}$, Matheus da Silva Araújo ${ }^{3}$, Ademilson Coneglian ${ }^{4}$

${ }^{1}$ Discentes do Curso de Engenharia Florestal da Universidade Estadual de Goiás, Campus Ipameri, Ipameri, GO, Brasil. (cunhaflorestal@outlook.com)

${ }^{2}$ Professora mestre da Universidade Estadual de Goiás, Campus Ipameri, Ipameri, GO, Brasil.

${ }^{3}$ Mestrando do Curso de Pós-Graduação em Ciências Florestais da Universidade de Brasília, Campus Darcy Ribeiro, Brasília, DF, Brasil.

${ }^{4}$ Professor doutor da Universidade Estadual de Goiás, Campus Ipameri, Ipameri, GO, Brasil.

Recebido em: 06/04/2018 - Aprovado em: 10/06/2018 - Publicado em: 20/06/2018 DOI: 10.18677/EnciBio_2018A82

\begin{abstract}
Devido à expansão de plantios florestais surge à necessidade de realizar análises de viabilidade econômica que demostram a aplicação racional dos recursos e também, de formulação de estratégias para administrar com eficiência e eficácia uma unidade produtiva florestal. Desse modo, o presente trabalho teve como objetivo analisar a viabilidade econômica da implantação do eucalipto VM01 para produção de lenha. A área corresponde a 10 hectares e está localizada no município de Ipameri, Goiás. $\mathrm{O}$ híbrido do eucalipto implantado será obtido através de mudas e plantado no espaçamento de 4 × 1,5 metros, totalizando 1.6667 mudas por hectare, em ciclo de 7 anos. Para esse estudo de viabilidade utilizou os seguintes indicadores econômicos: Índice Benefício Custo (IBC), Valor Presente Líquido (VPL) e aplicação do Payback econômico do capital investido. A taxa de retorno utilizada foi de $10 \%$ e o tempo de diagnóstico foi de 7 anos. Obteve-se um custo total para a implantação do projeto em 10 hectares de $\mathrm{R} \$ 90.550,3$. Enquanto que a receita atingiu $R \$$ 140.285,60 obtendo um valor presente líquido de $R \$ 49.735,30$. O Payback foi verificado no $7^{\circ}$ ano e a razão $B / C$ foi de 1,5 . Diante disso, conclui-se que a implantação do projeto é economicamente viável indicando ser uma boa opção de investimento.
\end{abstract}

RESUMO

PALAVRAS-CHAVE: Economia florestal, indicadores econômicos, povoamentos de eucalipto.

\section{ECONOMIC VIABILITY OF THE PLANTING OF EUCALYPTUS VM01 FOR FIREWOOD PRODUCTION}

\begin{abstract}
Due to the expansion of forest plantations arises the need to conduct economic feasibility analyses that demonstrate the rational application of resources and also the formulation of strategies to manage efficiently and effectively a production unit forestry. Thus, the present work had as objective to analyze the economic feasibility
\end{abstract}


of deployment of eucalyptus for firewood production VM01. The area where the study was simulated corresponds to 10 hectares and is located in the municipality of Ipameri, Goiás. The eucalyptus hybrid deployed will be obtained through seedlings and planted in $4 \times 1.5 \mathrm{~m}$ spacing totalling 1.6667 seedlings per hectare, in 7-year cycle. For this feasibility study used the following economic indicators: index (IBC) Cost Benefit, net present value (NPV) and application of the Economic Payback of capital invested. The rate of return of $10 \%$ was used and the time of diagnosis was of 7 years. It was obtained a total cost to implement the project in 10 acres of $R \$ 90,550.3$. While the recipe $R \$ 140,285.60$ getting a net present value of $R$ $\$ 49,735.30$. The Payback was checked in 7 th grade and the $B / C$ ratio was 1.5 . Given this, it is concluded that the implementation of the project is economically feasible indicating a good investment option.

KEYSWORDS: Economy of Forestry, economic indicators, stands of eucalyptus.

\section{INTRODUÇÃO}

Nas últimas décadas foi evidente a expansão do gênero Eucalyptus sp. no Brasil, onde o país se destacou no comércio internacional como um dos principais produtores de celulose, atraindo dessa forma, muitos investimentos em pesquisa e produção (GONÇALVES et al., 2017). Desse modo, atualmente o país localiza-se na $4^{\circ}$ posição mundial entre os maiores produtores de celulose e sua contribuição ao PIB foi $\mathrm{R} \$ 69,1$ bilhões o que representa $1,2 \%$ da riqueza gerada no país (CNA, 2017). Sendo assim, os plantios florestais ocuparam nos últimos anos cerca de 5,98 milhões de ha. Sendo que 3,75 milhões foram ocupados com eucaliptos, 1,8 milhões com pinus e 425,2 mil ha com outras espécies. No qual, esses cultivos totalizaram aproximadamente $0,65 \%$ do território brasileiro (RODRIGUES et al., 2015).

Por meio das plantações florestais é possível obter várias fontes de matériasprimas que são extremamente importantes para diversos componentes industriais do ciclo produtivo da madeira, industrialização e comercialização, como celulose e papel, siderurgia, energia, painéis, móveis, madeira sólida, além de outros derivados, que expressam participação significativa e estratégica na economia nacional e na geração de empregos (SCHUCHOVSKI, 2003).

Dentre as espécies, a cultura do eucalipto se destaca como uma das mais importantes no Brasil, afinal, a mesma se enquadra em quase todos os prérequisitos almejados da produção e se adapta bem as condições favoráveis de clima e de solo, além do país apresentar grande extensão territorial e tecnologias avançadas na silvicultura das espécies. Sendo possível produzir comercialmente o volume de até $45 \mathrm{~m}^{3} / \mathrm{ha} / \mathrm{ano}$ de madeira, superando países como Uruguai, Indonésia, Chile, Estados Unidos, Canadá e Espanha (SOARES et al., 2010).

A madeira é um dos fundamentais recursos naturais e existe praticamente em todas as regiões. No entanto, o uso da mesma como fonte energética pela humanidade, existe desde o princípio, principalmente quando se refere a sua forma bruta, tradicionalmente conhecida como lenha (BRITO, 2007). Porém, apesar de sua antiga utilização, a mesma não caiu em desuso e é amplamente utilizada para diversos fins, sendo umas das fontes mais competitivas quando considerada sua relação benefício/custo (BUAINAIN; BATALHA, 2007).

No entanto, em qualquer operação que aplique a madeira como matéria-prima é necessário que se faça um planejamento florestal criterioso de todas as atividades envolvidas no processo de produção para que resulte em menor custo de risco, minimização dos custos operacionais, melhoria da produtividade de trabalho, racionalização do fluxo de produção e aumento de rentabilidade (CARMO et al. 
2011). Destacando dessa forma, a necessidade de realizar análises de viabilidade econômica que demostram a aplicação racional dos recursos e também, de formulação de estratégias para administrar com eficiência e eficácia uma unidade produtiva florestal (SOUZA, 2010).

Diante do exposto, em razão da escassez de informações relacionadas à viabilidade econômica da implantação da cultura do Eucalipto, o presente trabalho teve por objetivo analisar os custos e receitas da implantação de eucalipto para produção de lenha em uma área experimental na Universidade Estadual de Goiás Câmpus Ipameri.

\section{Área de Estudo}

\section{MATERIAL E MÉTODOS}

O experimento foi simulado em uma área experimental na Universidade Estadual de Goiás, Campus Ipameri (coordenadas geográficas; $17^{\circ} 43^{\prime}$ 19" latitude S e $48^{\circ} 09^{\prime} 35^{\prime \prime}$ longitude W; e altitude de $764 \mathrm{~m}$ ). O município de Ipameri está localizado na região sudeste do estado de Goiás, onde o clima é classificado como Aw (tropical estacional) com precipitação anual de aproximadamente $1600 \mathrm{~mm}$, sendo caracterizado por duas estações bem definidas, uma seca no inverno e uma chuvosa no verão, e com temperatura média de cerca de $23^{\circ} \mathrm{C}$ (ALVARES et al., 2013).

O talhão que foi destinado a implantação da cultura possui 10 hectares. $O$ espaço se localiza próximo a logradouros que possuem livre acesso, facilitando dessa forma, o transporte do material para o seu destino final. Além de se estabelecer próximo ao Campus, facilitando as análises e pesquisas.

\section{Manejo da cultura}

Para a implantação do plantio foram coletadas amostras de solo da área para análise química em laboratório. Com base na análise (Tabela 1), foram estimados os cálculos de adubação e calagem através da recomendação para o uso de fertilizantes da cultura do eucalipto (RIBEIRO et al., 1999) e do método de saturação por bases, para correção dos níveis de fertilidade e acidez do solo. Posteriormente, atividades como controle de formigas, limpeza da área, calagem, aração e gradagem, bem como a marcação de linhas para o plantio das mudas em sulcos foram mensurados os custos.

TABELA 1. Características químicas do Latossolo Vermelho-Amarelo distrófico, antes da simulação do projeto.

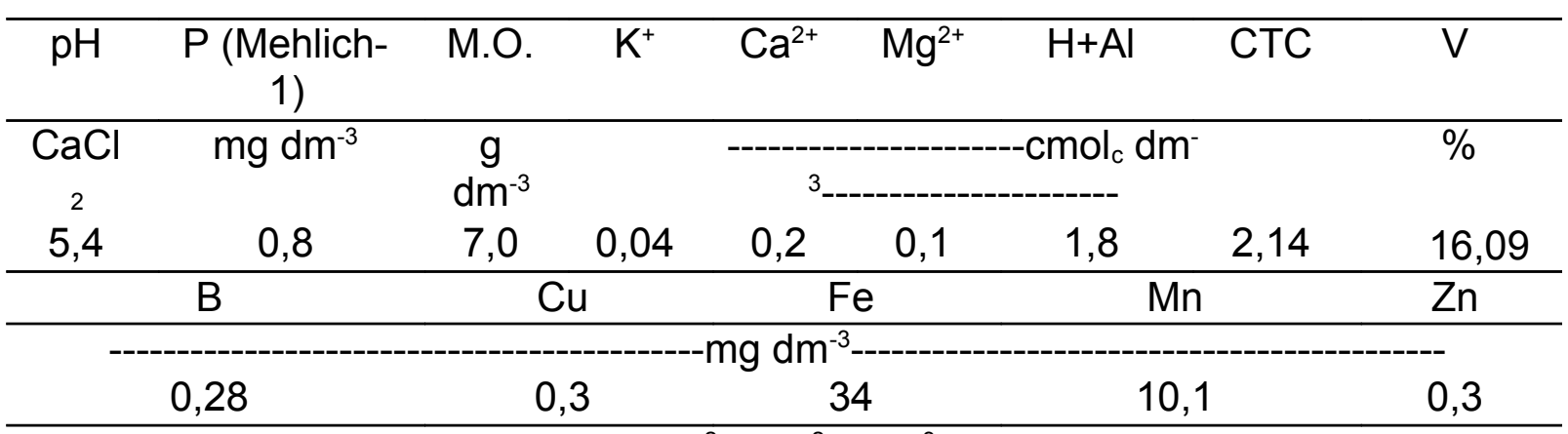

Extratores: $\mathrm{P}, \mathrm{Na}$ e $\mathrm{K}$ - Mehlich-1; $\mathrm{Ca}^{2+}, \mathrm{Mg}^{2+}$ e $\mathrm{Al}^{3+}-\mathrm{KCl} 1 \mathrm{~mol} / \mathrm{L} ; \mathrm{H}+\mathrm{Al}-$ Acetado de cálcio $0,5 \mathrm{~mol} / \mathrm{L}$ a pH 7,0 . 
O híbrido do eucalipto implantado foi VM01, no qual, foi obtido através de mudas e plantado no espaçamento de $4 \times 1,5$ metros, totalizando 1.6667 mudas, em ciclo de uma rotação com idade de corte de sete anos.

É notório que a irrigação em plantações de eucalipto são de extrema importância para garantir a sobrevivência das mudas, principalmente após o plantio, para que a mesma se estabeleça de forma eficaz. No entanto, essa irrigação será periódica durante os primeiros meses de instalação, ou seja, como no caso em estudo o experimento será instalado no mês de outubro, a irrigação será realizada nos primeiros 15 dias do mês. No qual, serão colocados com auxilio de um tanque de arrasto três litros de água por muda em cada operação. $E$, além disso, se houver ocorrência de um veranico será realizada uma irrigação contínua para não ocasionar a mortalidade das mudas (ARRUDA et al., 2011).

A manutenção no segundo ano envolve atividades como coroamento de mudas, controle de formigas, manutenção de estradas e aceiros. Porém, a assistência realizada no terceiro ano envolve além desses processos anteriores, o mecanismo de roçada, técnica imprescindível para contribuir na limpeza da área. E a manutenção do quarto ao sétimo ano abrange controle de formigas, manutenção de estradas e aceiros.

A técnica de desbaste utilizada será o sistêmico aos sete anos de idade, onde todas as árvores em uma mesma linha serão retiradas sem prévia avaliação, com finalidade de uso interno e comercialização da madeira como lenha para queima em olarias e caldeiras da região (JANOSELLI et al., 2016).

\section{Coleta de dados}

Nesse estudo, as informações de orçamento foram obtidas pelos autores entre os meses de dezembro a março de 2018. O sistema de produção do eucalipto foi delineado ajustando as técnicas de entrevista a empresas e produtores, com auxílio de especialistas para ajustes e validação de sistemas elaborados para realizar planilhas com valores atualizados de todo o manejo de produção.

\section{Custos de Implantação}

Custos de implantação incluem mão de obra e combustível, correção de solo, controle de formigas, aplicações para controle de plantas invasoras, formulações de NPK, plantio e irrigação. Em que, esse valor foi estabelecido conforme os procedimentos realizados e o rendimento médio por homem. O combustível utilizado será estabelecido com a média de consumo de uma fonte de potência prédeterminada, dependendo de cada operação realizada, e o valor do litro do óleo diesel (ESALQ, 2015).

O combate inicial a formiga (Gêneros Atta e Acromyrmex) foi realizado com equipamentos manuais, com o primeiro controle antes do plantio e o segundo após três meses. Também foram adicionadas aos custos duas aplicações para controle das plantas invasoras, a primeira antes do plantio e a outra após dois meses, de forma mecanizada. Para a irrigação foram estabelecidas três irrigações via tanque de arrasto, para evitar perdas com possíveis estiagens. O plantio mecanizado será a forma empregada na área, devido ao rendimento e custo mais baixo.

\section{Custos de manutenção e comercialização da madeira}

Os custos de manutenção envolvem os gastos com mão de obra, combustível, adubações de cobertura, controle de formigas e de plantas invasoras. O controle de formigas (Gêneros Atta e Acromyrmex) foi realizado durante todo o 
período de 7 anos, por se tratar da principal praga e prejudicar do início ao fim a cultura (WILCKEN et al., 2008). Para os cálculos de comercialização da lenha foi estimada uma produtividade de $357 \mathrm{~m}^{3} /$ ha, comercializada a $R \$ 40,00$, valor cotado da região.

\section{Análise econômica}

Foram utilizados os indicadores tradicionais de análise econômica de projetos e investimentos, como: Valor Presente Líquido (VPL), Índice Benefício Custo (IBC) e aplicação do Payback econômico do capital investido. O índice Benefício/Custo refere-se a partir da comparação entre receitas e despesas totais atualizadas a uma taxa de juro, ou seja, é quanto se espera ganhar para cada unidade de capital investido. Sendo alcançado pela relação entre o valor da receita bruta e o valor líquido dos custos, oferecido em porcentagem (CARVALHO et al., 2016).

$$
B / C=\frac{\sum_{j=0}^{n} R_{j}(1+i)^{-j}}{\sum_{j=0}^{n} C_{j}(1+i)^{-j}}
$$

Em que: $R j=$ receita no final do ano $\mathrm{j}$;

$\mathrm{L}=$ taxa de desconto

$\mathrm{Ci}=$ custo no final do ano $\mathrm{j}$;

$\mathrm{N}=$ duração do projeto em anos.

Outro método para avaliar um investimento é o Payback atualizado. Nesta metodologia encontra o período que o investimento gasta para repor o capital investido. O payback pode ser definido como o resultado do tempo de retorno em razão do valor presente dos investimentos e valor presente dos lucros (VERGARA et al., 2017).

$$
\text { Pay back atualizado }=\frac{\text { Valor do Investimento }}{\text { Valor dos fluxos de caixa }}
$$

Enquanto que o valor presente líquido representa o valor das receitas menos o valor com o investimento inicial, quando o resultado for positivo constitui que o projeto é viável, pois o decréscimo do custo ou o retorno é maior do que o valor que foi investido (VERGARA et al., 2017).

$$
V P L=\sum_{j=0}^{n} R_{j}(1+i)^{-j}-\sum_{j=0}^{n} C_{j}(1+i)^{-j}
$$

Em que:

VPL - valor presente líquido;

$\mathrm{Rj}$ - valor atual das receitas;

Cj - valor atual dos custos;

i - taxa de juros;

j - período em que a receita ou o custo ocorrem;

$\mathrm{n}$ - número máximo de períodos. 


\section{RESULTADOS E DISCUSSÃO}

Com base nos dados obtidos estimou-se a composição dos custos necessários para a implantação do híbrido eucalipto VM01 em um hectare considerando um horizonte de sete anos. Observa-se, que os valores relacionados a insumos e serviços representam respectivamente $25,44 \%$ e $73,50 \%$ do custo total (Tabela 1).

Sendo assim, na composição dos custos relacionados aos insumos incluem atividades como: mudas para plantio, análise de solo, irrigação, gessagem, calagem e utilização de fertilizantes. Esses custos totalizaram $R \$ 2.303,80$ dos gastos, considerando uma área de um hectare. Na composição dos custos a atividade que representou maior gasto foi à aquisição de mudas para plantio e replantio $(43,4 \%)$ seguindo da irrigação $(21,70 \%)$.

No entanto, as práticas relacionadas aos serviços incluem atividades como: subsolagem e fosfatagem, calagem em geral, limpeza da área, plantio e replantio, combate a formigas, capina manual de coroamento, construção e manutenção de aceiros, aplicação de herbicidas e irrigação. Esses custos resultaram $\mathrm{R} \$ 6.655,00$ do custo total da produção. Entretanto, o custo que agravou a atividade relacionada aos serviços foi à construção e manutenção de aceiro (16,82 \%), seguindo da subsolagem e fosfatagem $(5,70 \%)$.

Os resultados obtidos nesse estudo foram semelhantes ao de Queiroz et al. (2016) na implantação de povoamento de eucalipto, no qual, o custo com serviços $(\mathrm{R} \$ 4.627,66)$ foi superior aos de insumos. Entretanto o custo total apresentado foi de $\mathrm{R} \$ 7.416,79$, valor $19 \%$ inferior ao custo total deste presente trabalho. Fato que pode ser explicado pelo número de árvores por hectare (1.111) utilizado pelos pesquisadores, uma vez que, o espaçamento utilizado no presente estudo $(4 \times 1,5)$ apresenta maior número de árvores (1667).

TABELA 1 - Estimativa dos custos de implantação do eucalipto por hectare em 7 anos.

\begin{tabular}{ccc}
\hline Componentes do custo & Valor/ha (R\$) & Participação (\%) \\
\hline Insumos & $2.303,80$ & 25,44 \\
Serviços & $6.655,00$ & 73,50 \\
Outras despesas (10\%) & 96,23 & 1,06 \\
\hline TOTAL (R\$) & $\mathbf{9 . 0 5 5 , 0 3}$ & $\mathbf{1 0 0}$ \\
\hline
\end{tabular}

A receita total foi obtida após a colheita, no sétimo ano da cultura atingindo um valor de $R \$ 140.286,60$. Durante esse tempo, os custos operacionais totalizaram $\mathrm{R} \$ 90.550,30$, com um retorno de $\mathrm{R} \$ 49.736,30$ por hectare (Tabela 2 ). Os gastos para a implantação da cultura nesse projeto podem ser explicados pelos baixos níveis de fertilidade do solo. Sendo que esse processo requer altas taxas de fertilizantes para a correção e mão de obra, que na maioria das vezes exigem uma grande quantidade de funcionários para a realização dos serviços em geral.

A irrigação e a manutenção da cultura ao longo dos anos, também são práticas que aumentam o custo operacional total. De acordo com Carmo et al. (2011) a definição dos procedimentos silviculturais e insumos necessários para o desenvolvimento satisfatórios da cultura, refletem em custos que dependem das características econômicas e sociais da região, e influenciam os gastos com mão de obra, aquisição e transporte de insumos. 
TABELA 2. Custos, receitas da implantação de eucalipto para produção de lenha em 145,2 hectares em 7 anos.

\begin{tabular}{cc}
\hline \multicolumn{2}{c}{ Custos e receitas em 10 hectares em 7 anos } \\
\hline Valor total de custos & $\mathrm{R} \$ 90.550,30$ \\
Valor total da receita & $\mathrm{R} \$ 140.286,60$ \\
Valor presente líquido & $\mathrm{R} \$ 49.736,30$ \\
\hline
\end{tabular}

De acordo com as análises realizadas das atividades, todos os critérios se demonstraram viáveis economicamente (Tabela 3 ). O VPL exibiu um valor de R $\$$ $49.736,30$ onde foi atribuída uma taxa de juros $6,75 \%$ que corresponde ao custo médio por hectare da produção do eucalipto. Esse valor foi superior ao VPL (R\$ 12.790,01 ha ${ }^{1}$ ) obtido por Virgens et al. (2015) ao avaliarem a viabilidade econômica de projetos de reflorestamentos com clones de eucalipto no estado da Bahia, tal resultado pode ser explicado pelo espaçamento utilizado no presente trabalho, onde foi cultivado um número maior de árvores (555 plantas) por ha, proporcionando maior produtividade e consequentemente maior retorno econômico.

Outro indicador analisado que demostra muita relevância nos estudos de custos é o B/C, onde esse apresentou ser viável economicamente. Indicando que para cada $\mathrm{R} \$ 1,00$ investido a uma taxa de desconto a $6,75 \%$, o retorno financeiro nesse sistema é de $R \$ 1,50$.

Além disso, vale ressaltar que nos últimos anos, a produção de madeira ficou mais cara no país conforme evidencia o relatório anual da Indústria Brasileira de Árvores (IBÁ). O qual constatou que em 2015, a inflação do setor de árvores plantadas, medida pelo Índice Nacional de Custos da Atividade Florestal (INCAFPoyry), foi de $12,8 \%$, enquanto que a inflação nacional medida pelo IPCA ficou em 10,7\% (IBÁ, 2017).

TABELA 3 - Análise Econômica dos critérios avaliados.

\begin{tabular}{cc}
\hline \multicolumn{3}{c}{ Análise econômica } \\
\hline VPL & $49.736,30$ \\
B/C & 1,50 \\
PayBack atualizado & 7 anos \\
\hline
\end{tabular}

A implantação da cultura do eucalipto para produção de lenha na área experimental da Universidade Estadual de Goiás é uma boa opção para geração de renda. Cabe salientar que, a prática de tal atividade em meios de crise e pouco investimento do governo fortaleceria o campus economicamente, podendo destinar a receita obtida em melhoria a universidade, como compra de materiais e aparelhos para pesquisa na universidade. Além disso, esta atividade seria de grande importância social e ambiental, bem como o desenvolvimento prático da silvicultura dos alunos de engenharia florestal e agronomia.

\section{CONCLUSÃO}

A implantação de eucalipto VM01 para produção de lenha apresenta baixo custo e bom retorno financeiro, sendo uma boa opção de renda para a universidade e pequenos produtores proprietários de terra da região de Ipameri, Goiás. 
A implantação de culturas florestais como eucalipto em áreas universitárias para comercialização, proporciona benefícios econômicos, sociais e ambientais para universidade e população.

\section{REFERÊNCIAS}

ALVARES, C. A.; STAPE, J. L.; SENTELHAS, P. C.; Gonçalves, M. L. M. e SPAROVEK, G. Köppen's climate classification map for Brazil. Meteorologische Zeitschrift. V. 22, n. 6, p. 711-728, 2013. Disponível em: <http://www.lerf.eco.br/img/publicacoes/Alvares_etal_2014.pdf>. doi: 10.1127/09412948/2013/0507

ARRUDA, O. G.; TARSITANO, M. A. A.; ALVES, M. C.; GIÁCOMO, R. G. Comparação de custos de implantação de eucalipto com resíduo celulósico em substituição ao fertilizante mineral. Revista Ceres, Viçosa, v. 58 , n.5, p. 576-583, 2011. doi: http://dx.doi.org/10.1590/S0034-737X2011000500007

BRITO, J. O. O uso energético da madeira. Estudos Avançados, São Paulo, v. 21, n. 59, p. 185-193, 2007. Disponível em: <https://www.revistas.usp.br/ eav/article/view /10215/11820> doi: http://dx.doi.org/10.1590/S010340142007000100015

BUAINAIN, A. M.; BATALHA, M. O. Cadeia produtiva de madeira. Brasília, DF: Ministério da Agricultura, Pecuária e Abastecimento: IICA, 2007. 82 p. (MAPA. Agronegócios, v. 6). Disponível em: <http://www.florestal.gov.br/snif/producaoflorestal/cadeia-produtiva > Acessado em 04 abr. 2018

CARMO, F. C. de A.; FIEDLER, N. C.; GUIMARÃES, P. P.; PEREIRA, D. P.; ANDRADE, W. S. de P. Análise de custos da implantação de cultivos de eucalipto em áreas acidentadas no sul do Espírito Santo. Cerne, v. 17, n. 4, p. 473-479, 2011. Disponível em <https://www.scielo.br/pdf/cerne/v17n4/v17n4a05.pdf>. doi: http://dx.doi.org/10.1590/S0104-77602011000400005

CARVALHO, L. C.; ESPERANCINI, M. S. T.; SANTOS, J. Z.; RIBAS, L. C. Análise comparativa de estimativas de custo de produção e rentabilidade entre sojas rr1 e rr2 pro/bt1. Revista Energia na Agricultura, v. 31, n.2, p.186-191, 2016. Disponível em: <https://revistas.fca.unesp.br/index.php/energia/article/view /2213/pdf_93>. doi: http://dx.doi.org/10.17224/EnergAgric.2016v31n2p186-191

CONFEDERAÇÃO DA AGRICULTURA E PECUÁRIA DO BRASIL (CNA). Brasil é um dos maiores produtores de florestas plantadas do mundo. Disponível em: $<$ http://www.cnabrasil.org.br/noticias/o-brasil-e-um-dos-maiores-produtores-de florestas-plantadas-do-mundo>. Acesso em: 21 dez. 2017.

Escola Superior de Agricultura - Luiz de Queiroz (ESALQ). Instruções para coleta e remessa de amostras. 2015 . Disponível em:< https://www.solos.esalq.usp.br/coleta.htm> Acessado em: 11 março 2018.

GONÇALVES, J. C., OLIVEIRA, A. D., CARVALHO, S. P. C., GOMIDE, L. R., Análise Econômica da Rotação Florestal de Povoamentos de Eucalipto Utilizando a Simulação de Monte Carlo. Ciência Florestal, v. 27, n. 4, p. 1339-1347, 2017. 
Disponível em:<https://periodicos.ufsm.br/cienciaflorestal/article/view/30 215/pdf>. doi: http://dx.doi.org/10.5902/1980509830215.

IBÁ - Industria Brasileira de Arvores (IBÁ). 2017. Relatório Ibá 2017. Disponível em: <http://iba.org/images/shared/Biblioteca/IBA_Rela torioAnual2016_.pdf>. Acesso em: 25 março. 2018.

JANOSELLI, H. R. D.; HARBS, R.; MENDES, F. L.; Viabilidade econômica da produção de eucalipto no interior de São Paulo. Revista iPecege. v. 2 , n. 2,p.2445, 2016. Disponível em:<https://revista.ipecege.com/Revista/article/view/65/49> doi:10.22167/r.ipecege.2016.2.24

RIBEIRO, A. C.; GUIMARÃES, P. T. G.; ALVAREZ, V. H. Recomendações para o uso de corretivos e fertilizantes em Minas Gerais - $5^{\circ}$ Aproximação, Viçosa, MG, 1999, 359p.

RODRIGUES, E. L.; ELMIRO, M. A. T.; JACOBI, C. M.; LAMOUNIER, W. L. Aplicação do modelo SWAT na avaliação do consumo de água em áreas de florestas plantadas na bacia do rio pará, Alto São Francisco, em Minas Gerais. Sociedade \& Natureza, v. 27 n.3, 2015. Disponível em: < https://www.scielo.br/pdf/sn/v27n3/0103-1570-sn-27-3-0485.pdf> doi: http://dx.doi.org/10.1590/1982-451320150309

SOARES, N. S., SILVA, M. L. DA, REZENDE, J. L.P. DE, GOMES, M.F. M. Competitividade da cadeia produtiva da madeira de eucalipto no Brasil. Revista Árvore Viçosa, n. 34, n. 5, p. 917-928, 2010. Disponível em: < https:// www.scielo.br/pdf/rarv/v34n5/17.pdf> doi: http://dx.doi.org/10.1590/S010067622010000500017

SOUZA, F. Custos de produção agrícola: A metodologia da CONAB. Brasília, 2010. Disponível em: < https://www.conab.gov.br>. Acesso em: 21 jan. 2018.

SCHUCHOVSKI, M. S. Diagnóstico e planejamento do consumo de madeira e da produção em plantações florestais no Estado do Paraná. 2003. F. 78. Dissertação (Mestrado em Engenharia Florestal)-Universidade Federal do Paraná, Curitiba, 2003.

VERGARA, W. L H.; OLIVEIRA, J. P. C.; BARBOSA, F. A.; YAMANARI, J. S. Análise de viabilidade econômico-financeira para aquisição de uma unidade de armazenagem de soja e milho. GEPROS. Gestão da Produção, Operações e Sistemas, n.1, p. 41-61, 2017. Disponível em: <https://revista.feb.unesp.br> doi: 10.15675/gepros.v12i1.1598

VIRGENS, A.P.; FREITAS, L. C.; LUZ, D. S.; MOREIRA, A. C. D. Análise econômica e de sensibilidade em projetos de reflorestamentos no Estado da Bahia. Enciclopédia Biosfera. v. 11, n. 21, p. 120, 2015. Disponível em:<https://www.conhecer.org.br/enciclop/2015b/agrarias/analise\%20economica $\% 20$ e $\% 20$ de $\% 20$ sensibilidade.pdf>. 
WILCKEN, C.F.; LIMA, A.C.V.; DIAS, T.K.R.; MASSON, M.V.; FERREIRA F. P.J.; POGETTO, M.H.F.A. 2008. Guia prático de manejo de plantações de eucalipto. Disponível em: < https://www.iandebo.com.br/pdf/plantioeucalipto.pdf>. Acesso em: 11. jan. 2018. 